\title{
Orthopedic Surgical Procedure
}

National Cancer Institute

\section{Source}

National Cancer Institute. Orthopedic Surgical Procedure. NCI Thesaurus. Code C16186.

A surgical procedure to treat and correct deformities, diseases, and injuries to the skeletal system, its articulations, and associated structures. 